\title{
WCC 2017-C-110: CTO \& BIFURCATION STENTING
}

\section{A.Sivaramakrishna}

Adinarayana $47 \mathrm{M}$ of age, HTN, diagnosed as CAD with Chronic stable angina ECG shows ST depressions anterior leads $2 \mathrm{~d}$ echo shows hypokinesia in LAD territory \& Mild LV systolic dysfunction CAG shown LAD Proximal total occlusion RAMUS Proximal 90\% LCX dominant distal 90\%, RCA Non dominant LMCA was engaged with 7F EBU3.0, LAD lesion was crossed with PILOT 50, 0.014*190CM ramus was crossed with BMW $0.014^{*} 190 \mathrm{~cm}$ LAS was Predilated $1.5^{*} 8$ \& $2.0 * 8 \mathrm{~mm}$, RAMUS was dilated with $2.0 * 8$ simultaneous 2 stents in LAD RAMUS in $\mathrm{V}$ Stenting stataregy with supraflex 2.75*40, RAMUS indolimus $2.75^{*} 24 \mathrm{~mm}$ respectively, Post dilatation in LAD $3.0^{*} 12$, Ramus $2.75^{*}$, final kissing was done. Post stent TIMI III flow achived.

CAG :
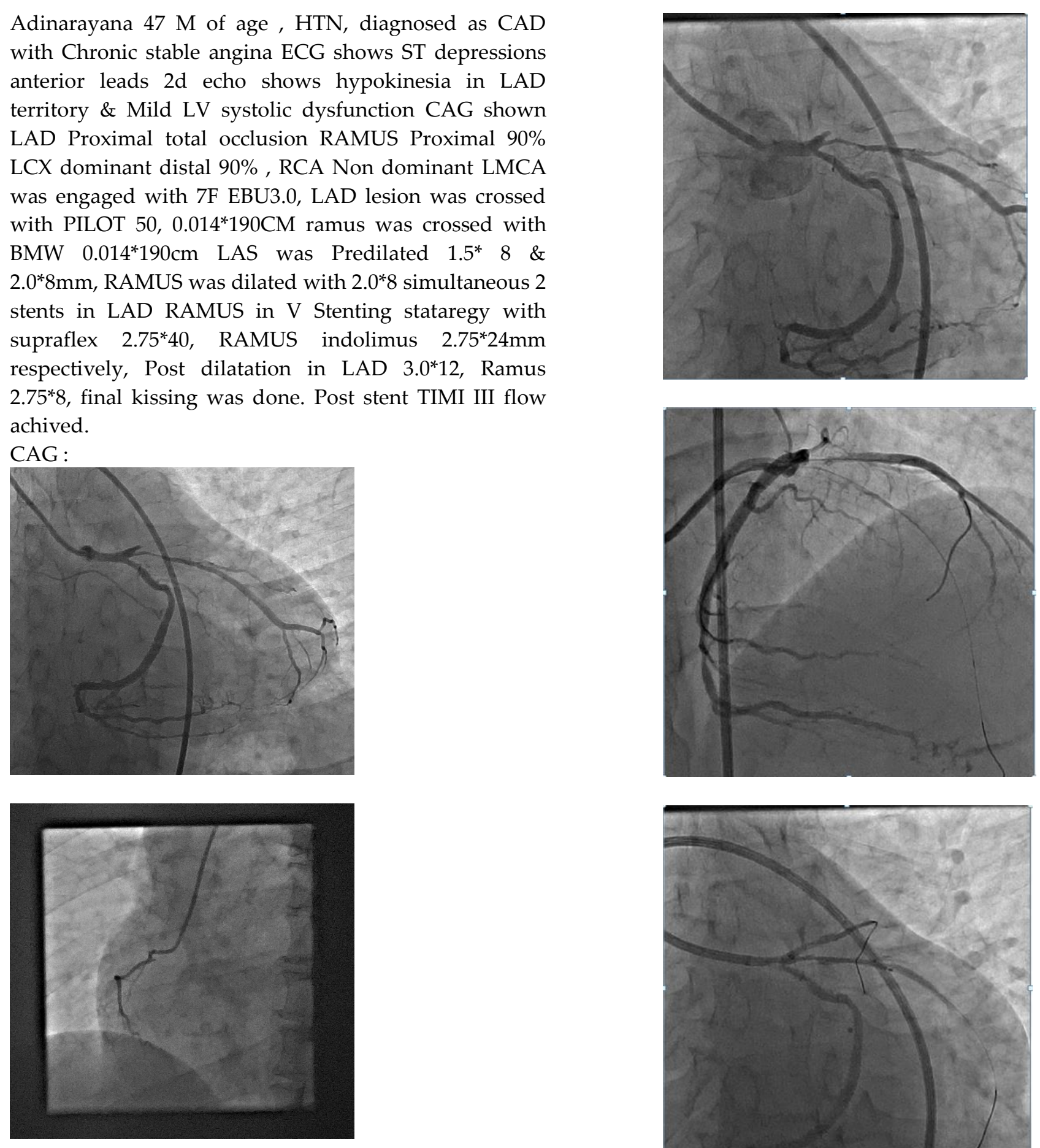

Article received on 01 JAN 2017, published on 31JAN 2017.

A. Siva Rma Krishna ${ }^{1}$

${ }^{1}$ Assistant Professor, Department of Cardiology, Guntur Medical College, India Corresponding Author: A. Siva Rama Krishna

Email: drsrkarikeri@gmail.com

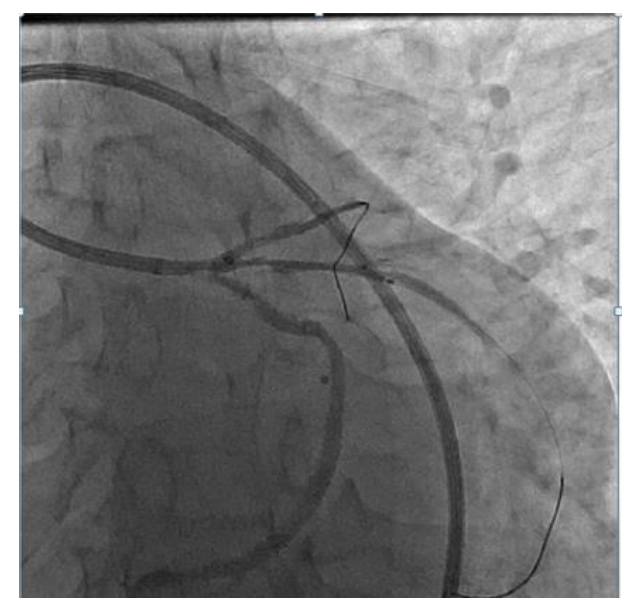



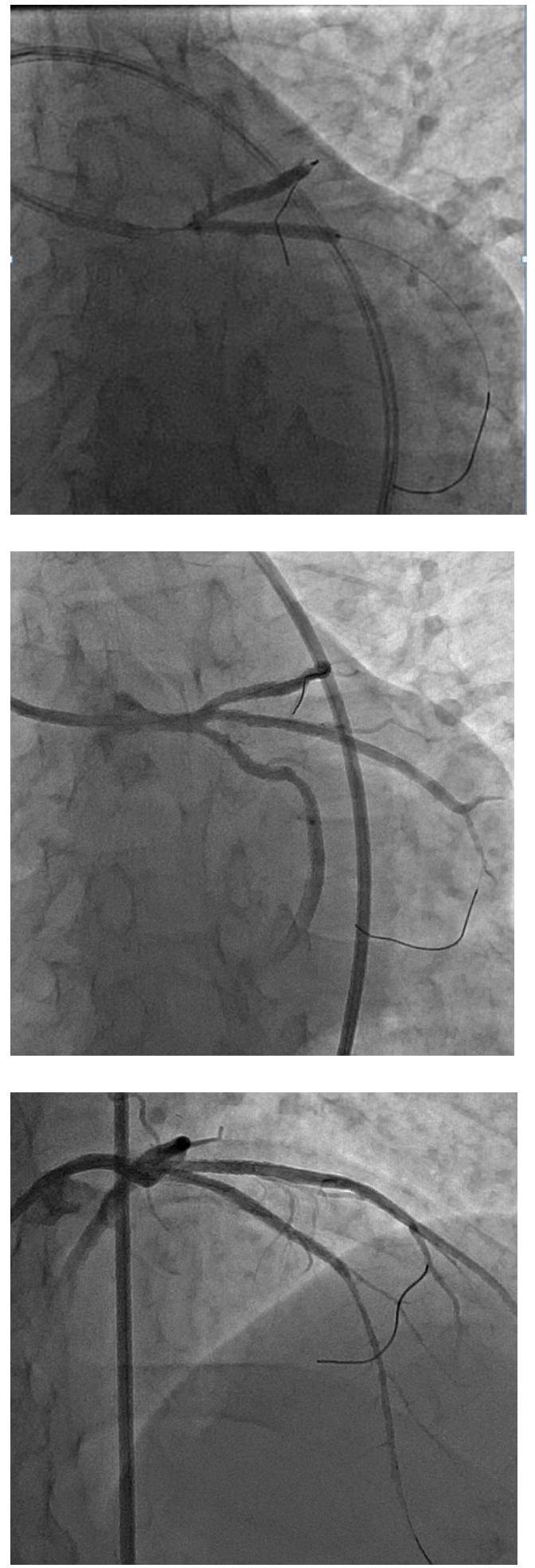
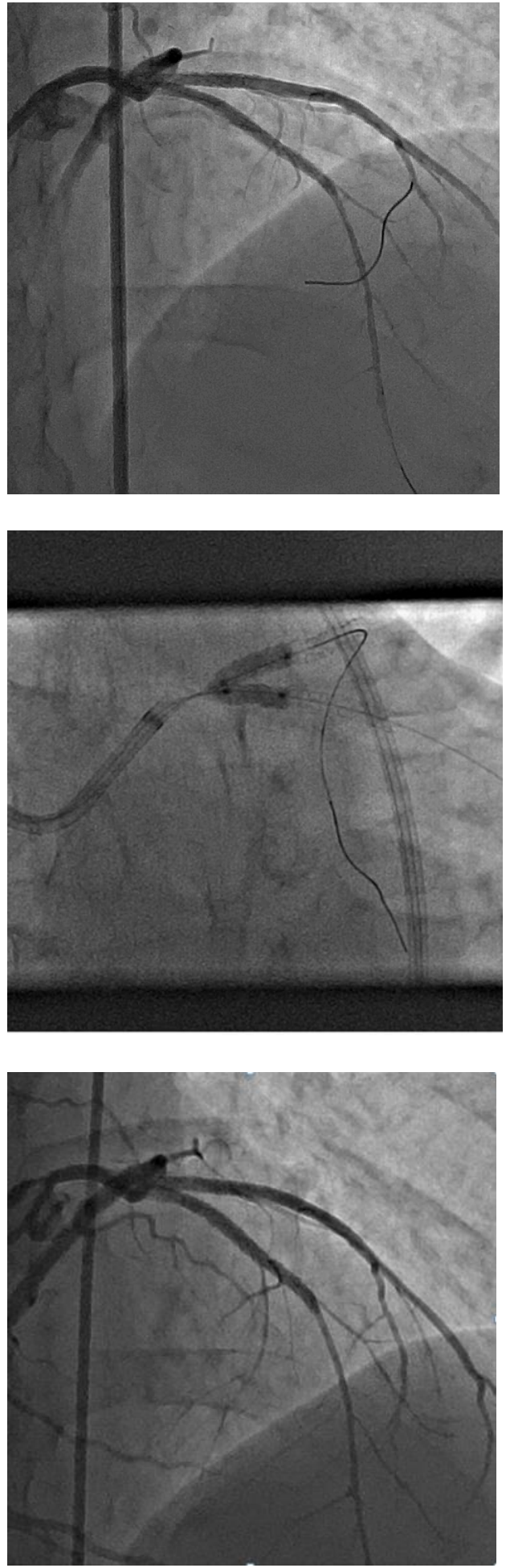